\title{
Policy approaches
}

\section{The post-modern research system}

\author{
Arie $\mathbf{R i p}$ and Barend $\mathbf{J} \mathbf{R}$ van der Meulen
}

The landscape of science is changing radically. In particular, there is increasing heterogeneity of actors, research sites, knowledge and networks. Science policy-makers have to respond to these changes, but heterogeneity makes it more difficult to impose own goals on the research system. Yet, if the dynamics in and of the system are understood, other policy approaches become possible. Here two inportant systemic aspects of research systems - 'steering' (the extent to which the system is sensitive to attempts of a principal, generally the state, to implement own objectives) and 'aggregation' (the organisation of processes of agendabuilding within the system) are introduced. It is argued that, because of the changes in science, a post-modern research system is both possible and desirable in which aggregation is favoured over steering.

Arie Rip and Barend J R van der Meulen are at the School of Plilosophy and Social Sciences, University of Twente, PO Box 217, 7500 AE Enschede, The Netherlands.

This article is an edited version of a paper presented at the international conference on Research Policies for Europe's Future: Strategies and Perspectives, Paris, 28-29 September 1995.
THE TERM 'RESEARCH SYSTEM' is of the late 20th century, and was used first in science policy. The OECD (Organisation for Economic Co-operation and Development) studies of 'the research system' in the early 1970s built on a way of speaking and thinking that was already common then (and can also be seen in the country reports produced by OECD since the late 1960s). These studies pursued their descriptive and diagnostic goals without explicit conceptualisation of what a 'research system' would be. ${ }^{1}$

'Systems' terminology is now common in science and innovation policy analysis, but still without real theoretical and empirical elaboration. This is, we think, a missed opportunity, not just intellectually, but also for policy. Analysis of long-term developments of systems, combined with synchronic analysis of functioning of systems (in different countries) allows diagnosis at a deeper level.

This is all the more important because of farreaching and radical changes in scientific research, its organisation and linkages with socicty, and the helplessness of policy actions in the face of these changes. Policy-makers need not feel helpless, but we would characterise the bravura of short-term assertive action without understanding long-term dynamics as de facto helplessness.

A key feature of these changes is the increasing heterogeneity: traditional categories such as 'basic' and 'applicd' research cannot be used any more; institutional locations of basic research such as universities take up other functions, while industrial research and new actors such as consultants and environmental centres are contributors to new knowledge; disciplinary demarcations are becoming obsolete, and the frontier of the advancement of knowledge lies with new combinations; researchers 
and research products move about in much broader networks; new actors get involved in the research system. ${ }^{2}$

In this paper, we will not address the issue of transformation of research systems directly. Instead, we shall explore the potential of the 'systems' approach, introduce a conceptual frame for empirical comparisons, and only after this detour discuss the way research systems are responding to increasing heterogeneity.

We shall compare the (national) research systems of seven industrialised countries. Nelson has noted the dangers of comparative studies (in his case, of national innovation systems) "in the absence of a well-articulated and verified analytic framework". 3 The first aim of the paper is therefore to develop the concept of a (national) research system so that such a framework can be formulated.

The second aim is to locate the (seven) countries studied here on a map, and discuss the transitions involved in responding to heterogeneity. In fact, we will argue that a more distributed, but still coherent, research system is viable, and call this a post-modern research system. Despite the difficulties such a system will present to policy-makers intent on centralised control, going along with the heterogeneities is to be preferred over attempts to reduce the complexities by imposing a 'master story' on the research system.

\section{Potential of (national) systems approach}

The concept of a 'national system of innovation' allows us to discuss the possibilitics (and missed opportunities) of a systems approach. Since its introduction by Freeman in the $1980 \mathrm{~s},{ }^{4}$ the concept of a national system of innovation has been used descriptively by policy analysts to enumerate the institutions, procedures and their functioning deemed to be relevant for innovation in a particular country. Thus, the concept functions as a checklist. This can be a useful exercise, but we should check for actual systems character. If the items on the checklist are not interdependent parts of a system, it makes no sense to attribute performance measures to the presumed national system of innovation.

When there are good reasons to assume the systems character, there is still the pitfall of a functionalistic view: that is, the view of an institutional set-up somehow geared toward innovation. There is no inherent purpose of the overall system to work towards innovative performance (or to some other goal). We have to inquire into the specific processes and mechanisms that make a system more or less productive.

In a more inductive route, comparative studies can be used to find out about differential productivity of systems. Again, without adequatc conceptualisation of processes and mechanisms, we are condemned to inferential reasoning of the form: if performance is high in country $X$, and low in country $Y$, a difference

\section{It is the interplay of factors and the overall set-up of the system which are decisive, so the conceptualisation of systems and their functioning has to include characteristics at the system level}

in the institutional set-up is sought for, and the differential performance attributed to that aspect. Whether there is indeed such a relation remains unclear. This is why Nelson pointed out the dangers of such quick comparisons. ${ }^{5}$

It is the interplay of factors and the overall set-up of the system which are decisive. So the conceptualisation of systems and their functioning has to include characteristics at the system level.

\section{Monitoring and assessment}

It is perfectly understandable that policy-makers want to monitor and assess the functioning (or quality, or health) of the system from the point of view of innovation-orientation and innovative performance (not only of firms), and want to use the concept of a national innovation system for that purpose. Idcally, a theory or a model is then needed of what is necessary/conducive to innovation. Not for particular innovations, where there is a mass of casc-study and comparative literature to build on, but for an overall system, and what we might call a functioning infrastructure for innovation.

Freeman, who introduced the concept, and Lundvall, who elaborated it, emphasised the historical development of national systems of innovation, and saw this as one of the explanations for the performance of a country. ${ }^{6}$ Implicitly, they refer to a competence that is built up and maintained over decades. Country studies often highlight this, but with ad hoc conceptualisations. ${ }^{7}$ For firms, a number of authors have emphasised their (dynamic) organisational competency as a key factor in explaining performance."

Broadening this notion and adding institutional competencies, we can view industrial or sectoral structure, in the structure-bchaviour-performance paradigm of industrial economics," similarly as a competence, though one not carried by an identifiable actor. ${ }^{10}$ Broadening the notion further, we can introduce competence at the level of countrics, at least for their research/innovation system, and ask what the nature of this competence must be to let the research/innovation system function and perform well.

\section{Sociological approach}

For national innovation sy'stems, a thcory or model specifying the nature of such competence is not 
available yet. The inductive route followed by Nelson's team in their country studies did not lead to articulation of a proto-theory. The 'knowledge systems' approach has remained at the level of an 'accounting system', or a checklist type of approach..$^{11,12}$

A more sociological approach is to see systems as evolving mutual interdependency systems. ${ }^{13}$ Interdependencies define what is part of the system, rather than standard items on a checklist. In stable situations, interdependencies have crystallised out and a checklist approach may be acceptable - if actors and/or analysts have arrived at an adequate list.

In times of change, the nature of interdependencies and boundaries evolve, and it is dangerous to use a standard classification. Think of how software innovation does not yet appear in R\&D and patent statistics, while analysts have been drawing attention to this question for some time. ${ }^{14}$ Actors may disagree about what properly belongs to the system; with globalisation there are real problems of interdependency.

The interdependency approach is additionally important because it highlights the by now wellrecognised fact that linear causality (factors $\mathrm{X}, \mathrm{Y}$ and $Z$ leading to high performance) will be the exception, rather than the nule. The implication is that the productivity of processes has to be sought in couplings and feedback loops rather than in features of the processes by themselves (compare the chainlink models of innovation and the overall analysis in $\left.\operatorname{OECD}(1992)^{15}\right)$.

\section{Preparing the ground}

This brief discussion of the concept of a national system of innovation and a proto-theory of its performance prepares the ground for our analysis of (national) research systems.

One immediate point is that, compared with the working definitions as in OECD (1972), ${ }^{16}$ sociological aspects should be included. If research systems are mutual dependency systems they will include not just the organisation of science, but also ongoing scientific work, its results and their 'cognitive institutionalisation', scientific communities, reward systems and so on. That the boundaries of such a "research system' are not static, but relate to evolving dependencies, is clear from the example of industry (industrial research as well as spokespersons for industry), which may now well be included in the research system to some extent. Similarly, patient associations have become actors in rescarch policy and sometimes also in organisation and management in the medical research sector.

A second, related point is that the working of research system(s) differs across scientific fields and societal sectors, as well as across countries. It will not necessarily be a national research system. National boundaries are important for resource relationships, organisations and policy-making, but there are other interdependencies as well, with scientific fields and with international organisations. So whether there is a national research system, is an empirical question.

A third point is that the research system, as a system, is not given as such, but always an outcome of interactions (including conflicts) and evolving institutionalisation. Particular features of research systems should then not be reified into 'factors', and comparisons should be made at the level of system features rather than specific factors that are present or absent.17

In this article, we attempt to identify such system features and use them for comparison and further analysis. We focus on the nature and functioning of (national) research systems, and go into questions of performance only when discussing viability of research systems in a changing world.

\section{Modern (national) research system}

(National) research systems consist of research performers (individuals, groups, institutions), other organisations and institutions, interactions, processes and procedures. Their systemic character, as mutual interdependency systems, is predicated on the collective character of the scientific endeavour, and on the role of the modern state which has created the 'national' character of these systems.

Here, we formulate two historical-causal hypotheses to capture the systemic features of the historical evolution, and we draw out two clusters of implications. While we will not go into detail here, the hypotheses and their implications can be filled in with sufficient historical and sociological materials to show their plausibility.

\section{Hypothesis 1}

The collective character of the scientific endeavour can be specified as self-organising science in context, that is, a combination of 'researching' on location, 'sciencing" in cosmopolitan fields, and 'politicking" and other resource mobilisation, ${ }^{18}$ and includes aggregation processes in relation to contexts.

There are two main aggregation processes. The first relates to scientific communities and includes organised scepticism, paradigm development and research agenda-building. The second relates to

\section{The two main aggregation processes are: scientific communities which includes organised scepticism, paradigm development and research agenda-building; and sponsors and external audiences inducing further agenda building and relevance articulation}


sponsors and external audiences (the state is one example, and by now an important one) which induce further agenda-building and relevance articulation. In both cases, local, contingent and tentative items are combined and selectively transformed into composites or aggregates with a cosmopolitan character. Such an aggregation process can be bottom-up, but may also be induced by other parties. ${ }^{19}$

Aggregation processes are supported by a socially distributed infrastructure of institutions and procedures, which itself will evolve and differentiate in relation to important contexts. Thus, there is a social component of aggregation as well: people and institutions become aggregated into collective actors with their own voice. ${ }^{20}$

\section{Hypothesis 2}

Since about 1870 , incentive structures for research performance have been created by (then emerging) modern national states, intentionally or as a sideeffect of other measures (for instance, in higher education). It was this intervention in (or collusion with) self-organising processes of science which created the typical modern national research systems.

The terminology "incentive structure" is derived from principal-agent theory, but actors need not think in those terms. In fact, some of these incentive structures were proposed and put into place by the agents - the scientists. The de facto incentive structures often institutionalise, or are set up as institutions in the first place (think of the big government-supported research institutes established in the late 19th century).

The important point is that these incentive structures do not disappear, but add up to an institutional landscape that enables and constrains the actors in their behaviour and eventual performance. This landscape also constrains the principals: new measures have to fit into what is out there already, or modulate it, or translate it. ${ }^{21}$

The two hypotheses together sketch a picture of evolving institutional landscapes and the competences embedded in them, which make up research systems with a national character. This picture is detailed further by drawing out two clusters of implications.

\section{First cluster of implications}

After 1870, institutions, groups and activities with a national scope become important in science. Science (in the sense of the performance of research, as well as the research products delivered, and the issue of the 'health' of what is now sometimes (inaccurately) called the science base) becomes important for the national state. The increasing interdependencies lead to the articulation and stabilisation of modern research systems with national scope; one indicator is the emergence of something like a national scientific community. ${ }^{22}$
In the modern research system, new types of institutions, such as research councils, become established; they mediate between science and the state, and reinforce the national aspect. As one commentator noted: research councils are "both a government bureaucracy and a parliament of the scientific community"23 - but this is a nationally defined scientific community.

\section{Second cluster of implications}

While specific actors, for example, in industry, in the health sector, and individual government agencies, interact directly with search practices and researchperforming institutions (this can have unintended system-level effects), the modern state influences the system directly (even if it does not always recognise where its actions will lead to). An important effect has been the emergence of an intermediary level, between the state, and research-performing institutions and ongoing research.

The intermediary level becomes increasingly populated (and this takes different forms in different countries). Research councils are now a prominent inhabitant of the intermediary level, but not the only one. Advisory bodies, programming bodies, standing review panels, are also intermediary in two senses: they mediate between state and performance of research, with only delegated authority at best; and they experience dual allegiance, to the state and to relevant scientific communities. ${ }^{24}$ Note that actors at the intermediary level need not be established by the state; associations of research-performing institutions and other collectives move at this level as well.

To speak of intermediary bodies as inhabiting a level indicates that this level is a system feature, with its own dynamics, and by now, a relative autonomy. The intermediary bodies, because of their relative independence from the state as general sponsor, can act as principals themselves, trying to get research performers to do what they want (even if what they want may be derived from the goals of the state). A further implication, important for our later argument, is that other generalised sponsors may induce further aggregation processes and research to go with it; the increasing importance of 'industry' is one example.

\section{Mapping modern research systems}

The institutional landscape of modern research systems and their functioning can now be characterised along two dimensions. For the first dimension, we use the label steering, because it relates to attempts of the state, as a principal, to have scientists and scientific communities work towards goals of the state. As a dimension, it does not refer to specific attempts at steering, and to the various analyses of science and national goals or national priorities, but to systemic features. The residues of such attempts, in institutions, linkages and patterns of behaviour, constitute 
the dimension. In other words, it captures the institutionalised 'competence' of the research system to respond to steering impulses: a composite incentive structure for scientists as agents and generalised sponsors as principals, and the style of the principal's approach as it has become embedded in the system.

The second dimension is labelled aggregation, and it refers to institutionalised processes of agendabuilding and the infrastructures for such processes. Bottom-up processes in research councils and other scientific organisations which lead to de facto priorities in research are one example. The recent interest in science and technology foresight activities provides more examples, for instance, in the Netherlands, while the Delphi exercises favoured in Germany should be seen as a service to principals, and thus linked to the stcering dimension. The UK is a mixed case: the foresight exercise has been set up as an incentive structure to move the agents, and functions that way. At the same time, the consultations and panels have stimulated aggregation activities. ${ }^{25}$

The two dimensions are composite, and operationalisation takes the form of synthesis scores (running from 5 (maximal) to 1 (minimal)). The assumption is that the items (as found in present research systems) used to characterise each of the two dimensions correlate sufficiently to be combined to form a single dimension.

\section{Dimension of steering}

The dimension of steering refers to institutional infrastructure and competences, not to actors' behaviour as such. Steering always has a principal, the state, with its own aims. ${ }^{26}$ Because the principal creates incentive structures for agents (research performers, now also bodies in the intermediary level) and in practice, also uses what is available already for such purposes, the effect is that an institutional infrastructure geared to steering exists and evolves further.

We can ask how much of such an infrastructure is there, and how well it functions. Part of the functioning relates to the way the principal positions itself. It can be strict in pushing through its aims or not, and the traditions and style of its positioning are embedded in the research system, and thus part of this dimension.

Synthesis scores are:

[5] The principal is emphatic about its own aims, and does not depend for them on the scientific community. Sanctions (budgetary or otherwisc) are built in: an example is the UK researchassessment exercise for universities. Intermediary-level bodies are held responsible for outputs related to the principal's aims, and thus tend to reproduce the principal-agent set-up in their relations with research performers.

[4] The principal has discretion to decide on its aims, but checks potential support (for example in study sessions of BMFT in Germany). Sanctions are

\section{Steering refers to institutional infrastructure and competences, not to actors' behaviour: aggregation, as a competence rather than an outcome, is the institutional infrastructure for processes of socially distributed agenda-building}

possible, and also positive incentives. Contracts (which are kept strictly) are an important instrument.

[3] The discretion of the principal to decide on its aims is limited to missions (but this can be an extensive part of the research system, as in the USA where government departments are important in funding and agenda-building). Calls for tender are used, but also network interaction. With research performers, contracts may be concluded (formally or informally - compare land grant colleges in USA, present-day contracts with universities and big research 'organismes' in France) but there are no strict performance checks.

[2] While the principal has a final say, especially when missions are concerned, it listens to signals from the research system, and stimulates bottomup agenda-building processes. Dialogue is more important than contracts. Intermediary bodies have their own responsibility, within overall limits.

[1] The principal prefers to support the bottom-up agenda, but checks whether agenda-building has been done properly. It is active in identifying opportunities for, and implementing, strategic turns in the research system (that is, strategic according to the perception of the principal). There is some dialogue, and a great deal of ad hoc intervention.

\section{Dimension of aggregation}

Aggregation, as a competence rather than an outcome, is the institutional infrastructure for processes of socially distributed agenda-building. Aggregation creates coherence, and infrastructures develop which support this. The existence of such infrastructures is an indicator of the extent of the dimension of aggregation. Bodies and processes in the intermediary level can play an important function. ${ }^{27}$

Agendas of research and other outcomes are not just protestations to the outside world. Actually, outsiders might be drawn into aggregation processes, especially if they are well established within institutions. They are effective (to varying extents) because they are (also) part of ongoing processes in the research performance world. Agenda-building and 
implementation are two sides of the same coin, so there is a link with socially distributed knowledge production.

Synthesis scores are:

[5] System-wide institutions with explicit aggregation tasks, which are recognised as such, and which function well. Networks and other linkages connecting different kinds of actors (university, research institutes, government, industry and other users of research) with actual agendabuilding activities. The Japanese Science and Technology Agency as a node in networks of consultation and agreement-seeking is a rare example. European foresight exercises are attempts to copy this but there is no institutional frame as yet.

[4] Institutions throughout the system have aggregation/agenda-building as an important or sole task. Overall co-ordination and agenda-building might happen as a result of communication and cooperation, but it is not institutionalised.

[3] Some organisations with a key role in the research system, often at the intermediary level, include aggregation/agenda-building among their tasks, or have this as a side-effect.

[2] Aggregation occurs within blocks/segments, but not across them and merely as a side effect of the occurrence of protected spaces. An example would be France, with the Grands Organismes as separate worlds, relatively protected from central-planning procedures from the government.

[1] No (institutionalised) aggregation. Aggregation is limited to traditional 'scientising'. Research performers position themselves individually (and compete in this way).

Using this operationalisation, the seven countries studied can be located on the two dimensions, and a

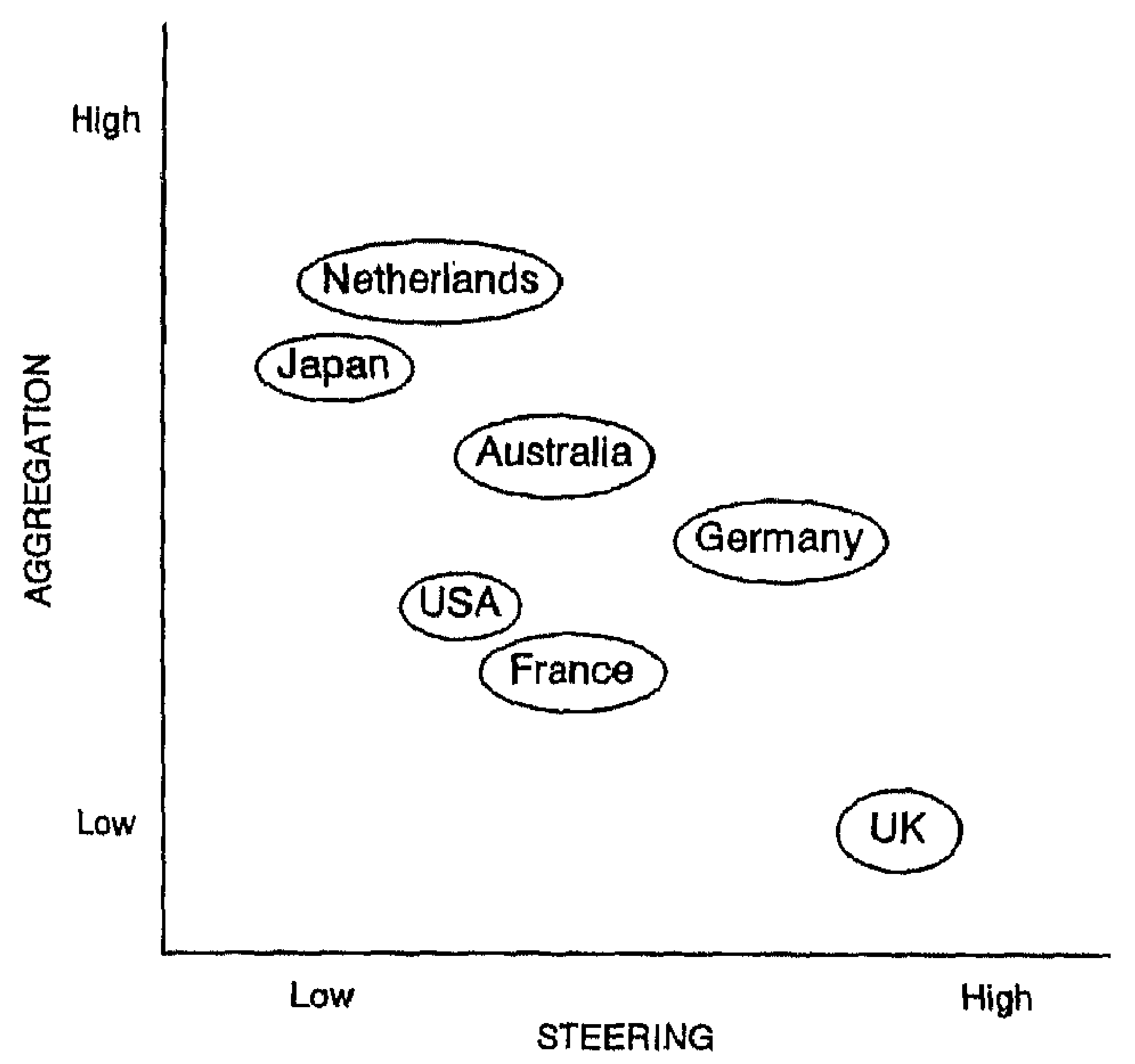

Figure 1. Map of seven countries studied in relation to aggregation and steering map can be produced (Figure 1). Country vignettes, briefly describing the institutional landscapes and their functioning, can be found in the appendix.

\section{Viable combinations}

Not all combinations of scores on the two dimensions are equally productive, and some combinations may not be viable at all over longer periods of time. (The assessment of productivity and viability depends, of course, on the goals and criteria that are used by the assessor.)

For example, highly institutionalised aggregation, while productive for normal purposes, can easily create closed-shop situations (old-boys networks in allocation of funds would be an example). This would make change, that is, the introduction and spread of novel actors and/or views, more difficult. It would also make it more difficult for the state, as a principal, to push its aims if these were different from what was being aggregated.

Modern research systems can be taken to have evolved from a situation of low stecring and low aggregation to a cluster of viable intermediate positions. Will they continue in this position? The combination of high steering and high aggregation would not be expected to be generally viable (for particular domains in particular periods, for instance, modern biotechnology in the 1980s, where there is both scientific and societal interest, the combination may work).

There is one instance of high steering and low aggregation on the map: the UK in recent decades. We might wonder whether this combination remains productive over longer periods of time, given the increasing heterogeneity of research and research systems? In this particular case, a master story was imposed by the Cabinet and its idcology on the research system, which created strong competition for resources. Recent activities, as in the foresight excrcise, may be stimulating aggregation again.

Some countries score high on aggregation and low on steering, and appear to do well. We can take this as an indication that further evolution of the modern research system to a new and viable position on the map is possible. ${ }^{28}$ In fact, it is desirable, since productive aggregation is necessary to handle the heterogeneity which is a feature of present changes without negating it. Call such a research system a postmodern' research system.

The idea of a new and viable position is argued here on the basis of instances that we happened to encounter, but it can be reformulated as the implication of earlier developments, a further historical-causal hypothesis.

\section{A third historical-causal hypothesis}

The evolution of the modern research system has created a well-developed institutional landscape, and 


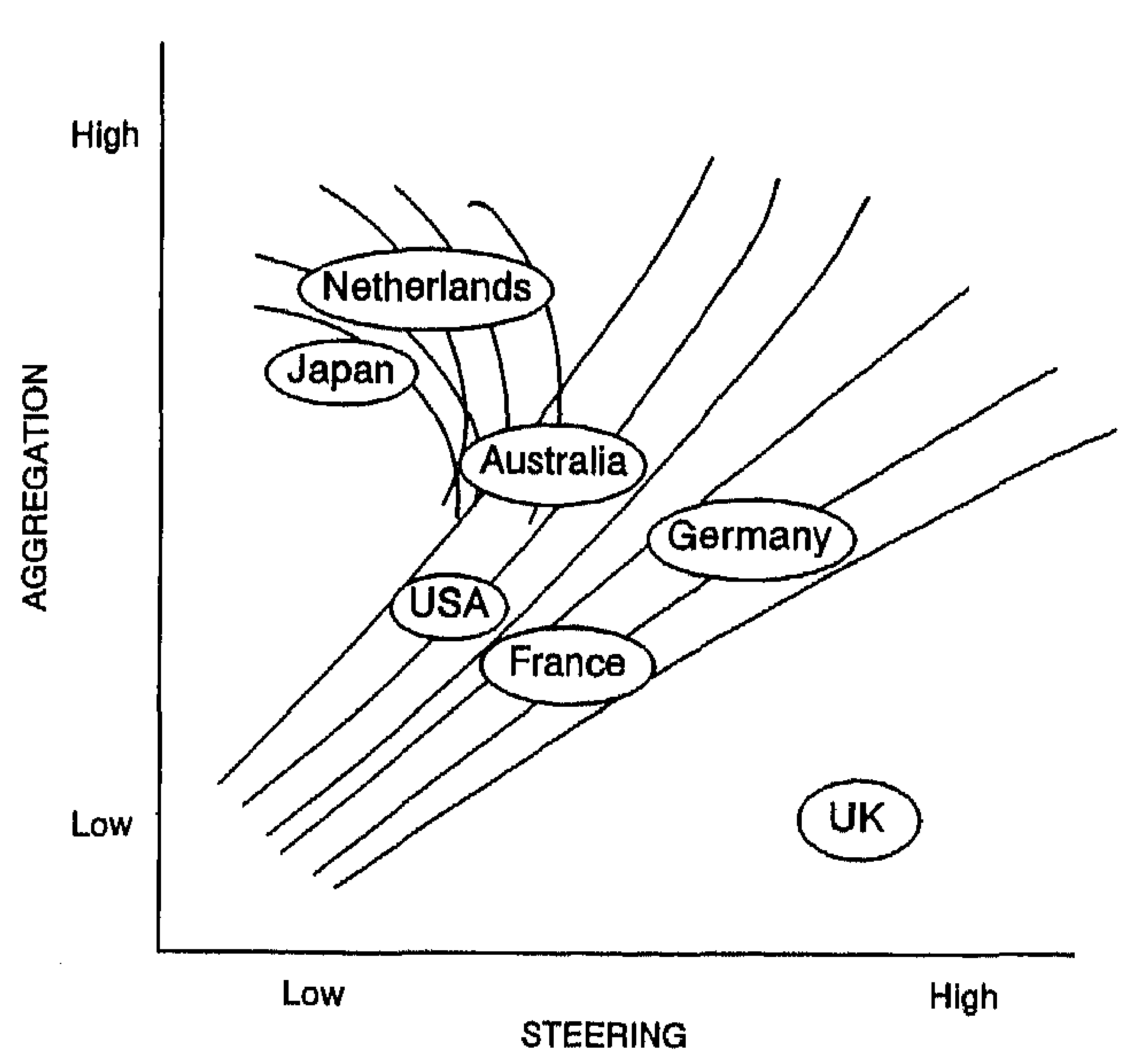

Figure 2. The path towards a post-modern system

a relatively autonomous intermediary level. Such a situation allows new interdependencies to be created, and the role of the state (with its specific steering modes) to become less dominant. ${ }^{29}$ One example would be the importance of other (generalised) sponsors: 'industry' (as a category to which to orient research) and 'sustainability'. In both cases, the traditional sequence of resource provider adding goals to the resource (the state as a patron of science) is reversed: goals/orientation of research come first, and this allows mobilisation of resources.

Thus, there are good reasons to see the new position as viable. Our hypothesis further suggests that all modern research systems can develop in this direction. In other words, a path toward such a post-modern research system branches out from the presently dominant type. This idea is visualised in Figure 2. Japan and the Netherlands, developing their modern research system in the late 19th and early 20th contury, differed from other countries because of their socio-political culture and structure. The opportunities to evolve into a post-modern research system were there.

The historical-causal hypothesis indicates the possibility of a development toward a post-modern research system, but is neutral with regard to its desirability. In our view, modern research systems will have trouble in accommodating the increasing heterogeneity of the production of knowledge (both its contents and its organisation ${ }^{30}$ ). If evolution towards a post-modern research system is indeed desirable, present changes in research systems should be assessed as to whether they are conducive to the transition.

In addition, one could articulate scenarios for the evolution of modem research systems to a (more) post-modem position. Of course, such changes cannot be brought about in a simple way, because they are bound up with socio-political cultures and structures of a country. The articulation of a transition scenario is important to be able to identify opportunities for change in the 'right' direction.

Accepting the desirability of a post-modern research system, we also face new challenges. Steering, in the strict sense, will become less important, but there is still a management challenge: multi-actor and non-centralised management of the evolving research system. For the state, this implies configurational management. ${ }^{31}$

The other challenge relates to the productivity of aggregation processes. Post-modern science accepts heterogeneity, but should still be quality controlled. The idea of distributed coherence provides an entrance point. ${ }^{32}$ So we should inquire into the dynamics of distributed coherence in research systems, and shape transition paths in such a way as to improve it.

\section{In conclusion}

We have developed what Nelson called for: "a wellarticulated and - somewhat - verified analytic framework". The exercise might be relevant to questions about national innovation systems as well, even if the situation there is more complex. Interdependency systems should be traced. Our guess is that such systems will indeed be found, but they will be of smaller scope (and perhaps of different complexion) than is covered by the present checklists for innovation systems.

Be that as it may, research systems, with their link to self-organising science, can be defined and studied more easily than national innovation systems. We have proposed and operationalised two systemic features, steering and aggregation, and shown that these features capture important aspects of national research systems. Even if this claim is contested, there is still the methodological point, that it is necessary, and possible, to analyse at the system level.

There are also limitations to our argument. We have not analysed the relationship with performance, in spite of our use of the notion of a research system that is 'doing well', which provided us with one of the stepping stones to the idea of a post-modern research system. It would be possible to extend the approach, and study the performance of the systems - and in broader terms than innovation. ${ }^{33}$ The multi-level character of the system should be taken into account, as well as feedback and feed-forward loops. Articulating, elaborating and checking causal stories about performance would be an appropriate method.

Our substantial point is the possibility of development in the direction of a post-modern research system. The particular label is less important than the idea of a transition path branching out to a viable position which offers an alternative to typically modern research systems, including alternative management approaches.

Whatever you may think of this speculative 
diagnosis, the underlying more general point is that the landscape of science and its institutions is changing, and for a variety of reasons. Policy has to respond to the changes, but from a diagnosis of the dynamics and an assessment of the value of possible futures. It is here that the synchronic and diachronic 'systemic' analysis presented in this paper shows its policy relevance.

\begin{abstract}
Appendix. Country vignettes
Sources include Nelson, 1993 (note 3); van der Meulen and Rip, 1994 (note 24); and Rip and van der Meulen, 1996 (note 25); and country-specific studies and documents.

\section{Australia $[2+, 3+]$}

While the federal level in Australia is relatively weak, for the research system it can introduce major changes, as when the 'unified system' (all tertiary education institutions become universities) was decreed. Otherwise, institutionalised steering is fairly low because of the fragmented responsibilities for science and the dominance of political considerations. ASTEC, the top-level advisory body for science and technology policy, has made important contributions, but is the victim of political and administrative vicissitudes.

The intermediary level is sparsely populated, one reason being the relatively short history of the Australian research system (post 1945 ). Both intermediary organisations (various research councils) and big research performing organisations (including CSIRO (Commonwealth Scientific and Industrial Research Organisation)) are actively positioning themselves and trying to contribute to agenda-building. While there are no system-wide institutions for aggregation, the net effect of these recent activities
\end{abstract} is almost the same.

\section{France $[2+, 2]$}

In spite of the image of centralised planning, steering is low. For research, central planning amounts to adding up what ministries and Grands Organismes want to do for their own reasons. The Colbertist tradition has the state establishing and funding research (and other) efforts, not necessarily steering them.

Special funding and special programmes for prestigious science and technology (such as aerospace) do express the principal's aims, and are grafted onto the system. Recent changes include a rethinking of the overall system, the need for more participation of scientists and scientific organisations in the preparation of policies, and the establishment of contracts (with diffuse/open-ended terms) between the state and research institutions.

The big blocks (universitles, Grands Organismes, programmes) are worlds unto themselves and used to be locked-in by vested interests. Recently, strategies are formulated and implemented, partly because of budget cuts and other pressures. Agenda-building occurs, although still sparingly across the blocks. The European-level programmes have mobilised actors and created new interactions.

\section{Germany $[3+, 3]$}

The German research system combines an emphasis on self-organisation in basic research institutions (constitutionally anchored) and strong steering of strategic research by the (Federal) BundesMinisterium für Forschung und Technologie (BMFT), now the BundesMinisterium for Bildung, Wissenschaft, Forschung und Technologie $(B M B+F)$. The states have responsibility for the universitles, and they also contribute to the funding of a number of research institutes. This institutionalised division of labour and of authority creates a certain rigidity in the system, even if the components are productive in their own terms.
The BMFT/BMB $F$ creates incentives and steering pressures, for example on the Grossforschungseinrichtungen, and has set up several exercises including a Delphi study (in collaboration with Japan) to define goals for the research system. The basic research part of the system remains largely unaffected, although there is participation in BMFT/BMB+F's stimulation programmes.

Aggregation can, on the one hand, build on the interactions between scientists and other actors in the system, for example in the long-standing links with industry through the scientific societies and through bilateral interactions. On the other hand, the aggregation processes reflect the overall compartmentalisation, in the sense that shared agenda-building towards the (federal) government is almost absent. Advice is requested, and scientists are involved in BMFT's study sessions.

Within the basic research component, the Deutsche ForschungsGemeinschaft and the Max-Planck-Gesellschaft see themselves as representing and supporting the best of science. When new programmes are being established, or new institutes discussed, there is ad hoc agenda-building. So, while there are many ad hoc interactions, actual agenda-building remains limited to within one organisation or component of the research system.

\section{Japan $[1,4]$}

While government initiatives have been important, from the late 19 th century on, to establish research institutions, a Science Council and (industrial) research associations, industry has been more active in research. So, while MITI (Ministry of International Trade and Industry) has been, and is, important in industrial policy, science policy has been low key, and more of the nature of offering infrastructural support. Deiphi and other prospective exercises (and a general willingness to consider long-term issues) build on, and reinforce, shared views rather than strengthening the principal's position.

Intermediary organisations such as the science and Technology Agency, with both a support and a co-ordinating role, function as a node in a much broader system of consultation and seeking of agreement which is related to general cultural patterns. So even without many institutions with explicit aggregation tasks, aggregation is quite strong.

\section{Netherlands $[1+, 4+]$}

The state has few aims of its own. "Making knowledge relevant for wealth creation" or "assessing academic research on its societal relevance" remain slogans, with no real attempts to force these views on the research system. In so far as steering occurs, it is in modulating and shifting ongoing aggregation processes, and creating incentives for what is considered to be strategically interesting. Steering is seen as doing what is good for the research system (often, in their terms), with occasional attempts to break through the conservatism.

Socia lly distributed agenda-building is part of Dutch culture, and is taken up by a number of organisations in the research system. Research council activities relied heavily on input from researchers. The Sectoral Advisory Councils (tripartite, and with agenda-building as their main remit) have been very successfut, and scientists continue to contribute freely to their work, which is an indicator of productive institutionalisation of aggregation processes.

(continued) 


\section{Appendix (continued)}

\section{United Kingdom $[4,1]$}

From the early 1970 s (starting with Rothschlld's customer-contractor principle) the tendency has been to reinforce the privileged position of principals. The state sets its own aims, for its own reasons, and is increasingly strict in implementing them. The recent mission-statements exercise, and re-arrangement of the research councils (directed from the Office of Science and Technology, and with strong industrial/business presence at the top) is a case in point.

The research-assessment exercise for the universities, and the top-down budgetary decisions, have created a situation in which universities (and departments within them) are struggling to get high scores to safeguard their funding. They are prepared to spend to buy professors who will (hopefully) enhance their score.

Privatisation of public research institutions (and 'market testing' of services) is part of the ideology. Strong protests (in essence, arguing that research is to some extent a public good and should be funded and organised as such) have temporised some measures, but not changed the ideology.

Aggregation has been effectively destroyed, but recently the setting up of the foresight exercise has created space for bottom-up agenda-building, and interactions appear to continue after the exercise.

\section{USA $[2,2+]$}

A dual situation exists in which the conduct of basic research is measured in terms of the model of private universities, jealous of their autonomy (even if they depend on the state and other sponsors for research support), and mission-oriented research can and will be steered by federal government departments (and their programmes). There is no overall science policy-making, in spite of recent attempts to link science with national/societal objectives.

National laboratories have to become more active, now that they cannot rely any more on support from their federal ministry or agency. The States play an increasingly active role in stimulating and orienting research.

Within the several institutions, aggregation occurs, for example the National Institutes of Health (with a strategic plan deriving from interaction with biomedical communities). Within the (clientele) networks of the DoD (Department of Defense), the DoE (Department of Energy), and the DoA (Department of Administration), there is joint aggregation, but in American political culture, the government departments will preserve their discretionary authority.

Centres and consortia, established on the initiative or with the blessing of government, are new locations for aggregation.

\section{Notes and references}

1. OECD, The Research System. Vol 1. France, Germany, United Kingdom (OECD, Paris, 1972); OECD, The Research System. Vol 2. Belgium, Netherlands, Norway, Sweden, Switzerland (OECD, Paris, 1973). OECD, The Research System. Vol 3. Canada, United States, General Conclusions (OECD, Paris, 1974).

2. Arie Rip, "An exercise in foresight: the research system in transition - to what?" in S E Cozzens, P Healey, A Rip, J Ziman (editors), The Research System in Transition (Kluwer Academic, Dordrecht, 1990) pages 387-401; M Gibbons et al, The New Production of Knowledge (Sage, London, 1994).

3. Richard R Nelson (editor), National Innovation Systems. A Comparative Analysis (Oxford University Press, New York and Oxford, 1993) page 4.

4. Christopher Freeman, Technology and Economic Performance: Lessons from Japan (Pinter Publishers, London, 1987). Christopher Freeman, "Japan: a new national system of innovation?" in G Dosi, C Freeman, R Nelson, G Silverberg and L Soete, Technical Change and Economic Theory (Pinter Publishers, London, 1988) pages 330-348.

5. See Nelson, note 3

6. See Freeman, note 4; B-A Lundvall, "Innovation as an interactive process - from user-producer interaction to national systems of innovation", in Dosi et al, see note 4, page 361 .

Compare also Pavitt on the long history of Japan's industrial competence, as being more important for its later success than the usual explanation of imitation of innovations elsewhere. Odagiri and Goto show in some detail how this competence is also important for imitation: K Pavitt, "The international pattern and determinants of technological activities", in S E Cozzens et al, see note 2, pages 89-102; H Odagiri and A Goto. "The Japanese system of innovation: past, present, and future, in R R Nelson, see note 3 .

7. See Nelson, note 3 .

8. The basic reference is A Chandler, The Visible Hand: The Managerial Revolution in American Business (Harvard University Press, Cambridge, MA, 1977). The question whether there is, indeed, a competency with a systemic character, that is, of the firm as a whole, can be asked for Chandler's analysis as well. Organising capability/competence is a label which captures a heterogeneous and varying set of factors, and it is not clear whether there is such a thing by itself. If it is no more than a label for a checklist, it cannot explain a firm's performance.

9. J S Bain, Industrial Organisation (Wiley, New York, 1959).

10. There will be spokespersons, though, and policy-making and action. Similarly a firm can be seen as interacting components,

most often given voice by its management and its board. From such a perspective, there is no principal difference between firms, industrial structures and national states.

11. B Holzner and J Marx, Knowledge Application: The Knowledge System in Society (Allyn and Bacon, Boston, 1979); William N Dunn and Burkart Holzner, "Introduction: toward knowledge systems accounting" ,Knowledge, $9(2)$, December 1987, pages 163-167. Introduction to theme issue.

12. There are possibilities of developing this approach by introducing additional concepts of 'knowledge reservoir' and 'epistemic communities'. See B J R van der Meulen and A Rip, "Science policy and utilisation of research. key concepts and insights", background paper to the Conference of Like-Minded Research Donors, Hoevelaken (Netherlands), 21-22 June 1994, commissioned by the Netherlands Ministry for Development Affairs.

13. Raymond Boudon, La logique du social, introduction a l'anaIyse sociologique (Librairle Hachette, Paris, 1979); Michel Crozier, Erhard Friedberg, Actors \& Systems. The Politics of Collective Action (The University of Chlcago Press, Chicago, 1980) (originally L'acteur et le système (Éd. Seull, Paris, 1977).

14. K Pavitt and P Patel, "The international distribution and determinants of technological activities", Oxford Review of Economic Policy, 4(4), 1988, pages 35-55.

15. OECD, Technology and the Economy. The Key Relationships (OECD, Paris, 1992).

16. See OECD, 1972, note 1.

17. Reasoning back from observed performance to explanatory factors - what actors offering causal stories are wont to do is possible, but it will now be embedded in a diagnosis of the overall functioning of the system.

18. For further discussion of self-organisation of science see: Wolfgang Krohn and Günter Küppers, Die Selbstorganisation der Wissenschaft (Suhrkamp. Frankfurt/M, 1989); Helga Nowotny, "Individual autonomy and autonomy of science, the place of the individual in the research system", in S E Cozzens et al, see note 2, pages 89-102. For the additional dimension of politicking, see A Rip, note 2 .

19. Recently, government agencies and other generalised sponsors have been interested in the articulation of research agendas, and actively mobilise scientists and other actors for that purpose. Foresight exercises are seen as an important input in such processes.

20. Chemistry provides an interesting example of this as well as other features of aggregation. New interactions, institutionalised linkages, shared agenda-building with (chemical) industry (and with pharmaceutical industry) in general occur (the 
differentiation took place between 1880 and 1930). Such institutionalised processes of aggregation are now available, and chemists have been very well self-organised in their positioning towards the state in the 1980s and 1990s (at least in NW Europe) that is, they have been able to speak with a single voice. The example of chemistry also shows that it is the emergence of generalised sponsors, in this case industry, which drives the emergence of institutionalised aggregation. and not the role of the state as authoritative decision-maker.

21. The success of the strategies of the principals will not only depend on the incentives they offer to agents, but also to their fit with the existing landscape. When the focus is on entrepreneurs/firms, the neglect of the evolving institutional landscape may be understandable (because entrepreneurs see themselves as free agents, as their own principals). in the not-forprofit sector, institutional arrangements are all important, but otherwise careful studies discuss the institutional context only as the opportunity set for the actors in that context not as a topic in its own right. See for example: G H J M Neelen, Principal-agent relations in non-profit organizations. A comparative analysis of housing associations and municipal housing companies in The Netherlands (University of Twente, Enschede, PhD thesis, 1994).

22. This is not like the usual notion of the scientific community as the group involved in a discipline or a speciality. In the discourse of science, there is also the idea of an international and cosmopolitan scientific community, transcending the disciplinary and speciality communities. If the latter are the weft, the national scientific communities are the warp of its fabric. The collection of national scientific communities, with their precarious aggregation, is the nearest equivalent to Polanyi's idea of a Republic of Science. See Arie Rip "The Republic of Science in the 1990s". Higher Education, 28, 1994, pages 3-23. An example of an institutionalised representation of such a scientific community at the national level is the French comité National de la Recherche Scientifique. See Jean-François Picard, La République des Savants. La recherche française et 1o CNRS (Flammarion, Paris, 1990). In other countries, the representation is shared by an Academy, advisory committees and research council boards, and self-styled spokespersons.

23. David Williamson, "Summary of the discussion: relations with other research institutions and the scientific community" , in OECD/DSTI, Meeting of Heads of Research Councils (OECD. Paris, 1992) pages 31-32.

24. Pim Fenger, "Research Councils: buffers under crosspressures", Research Notes from the Netherlands, 1992/1, pages 2-7; B J R van der Meulen and A Rip, Research Institutes in Transition (Eburon, Delft, 1994).

25. Arie Rip and Barend van der Meulen, Strategie-ontwikkeling en verkenningen. Vergelijkende analyse van ervaringen en praktijken in Nederland, Frankrijk, Engeland en Duitsland, background report (Overlegcommissie Verkenningen, Amsterdam, 1996).

26. Note that in this conceptualisation, the principal is blackboxed, in the sense that he is just posited to have goals. This might lead to a decisionistic view of the principal, attributing complete discretionary authority to it. However, although the state may have some autonomy in this respect, it is itself an agent of the people (in democratic theory, and in the parliamentary institutional set-up) or an agent of segments and interests in society (in neo-corporatist theory). In the latter case, the state may also be agent for the national scientific community, caring for its interest.

27. The working of the Deutsche Forschungsgemeinschaft, with its definition of Sonderforschungsbereiche, is an example. The Dutch werkgemeenschappen (standing disciplinary coordination and review panels) of the Dutch research council's foundations (now dissolved and replaced by staff-coordinated peer-review assessment of research proposals) are another example.

28. The scores for the Netherlands and Japan are the cumulative effect of their history and culture, not (or at least not necessarily) the outcome of a policy to reduce steering and stimulate aggregation.

29. Japan and the Netherlands both have an 'active state' (compared with the USA, for example), but their governance patterns are not the typically steering mode of an external principal of science.

30. Compare with Rip, 1990, note 2.

31. Compare with K Hanf and F W Scharpf (editors), Interorganizational Policy Making: Limits to Coordination and Central Control (Sage, London, 1978); E H Klyn, G Teisman, "Besluitvorming in beleidsnetwerken. Een theoretische beschouwing over het analyseren en verbeteren van beleidsprocessen in complexe beleidsstelsels" , Beleidswetenschappen, 6, 1992, pages 32-51.

32. Gibbons et al, The New Production of Knowledge; The dynamics of science and research in contemporary societies (Sage Publications, London, 1994) emphasise change and 'distributedness', but limit themselves to open phrases such as "quality control in mode 2 is different" (page 65) or suggestive but unspecified ideas as "overlapping local contextualisations" (page 109). They seem to glorify in the transient character of mode 2 , with only electronic networks to counteract fragmentation. Instead, one could take the distributed, but coherent character of such networks as an inspiration to think about post-modern quality control.

33. In addition to the immediate performance (scientific outputs, disse mination, embedding of science in society) societal quality could be introduced in terms of contribution to wealth creation, quality of life and societal learning. 'Wealth creation' and 'quality of life' have been put up front in the UK White Paper on science policy, which can be read as an explicit attempt to articulate goals for the national research system and developing instruments and structures to achieve these goals. See WWaldegrave, Realising our Potential. A Strategy for Science, Engineering and Technology, White Paper $\mathrm{Cm}$ 2250 (HSMO, London, 1993). In ourview, 'societal learning' is the essential third goal (if only to capture the cultural role of science and its role with regard to decision-making). 